OPEN ACCES

\title{
Cerium Oxide Nanoparticles Protects Gastrointestinal Mucosa From Ethanol induced Gastric Ulcers in In-vivo Animal Model
}

\author{
Rangabhatla Gunneswara Subramanya Vara Prasad ${ }^{1}$, Revathy Davan $^{1,2}$, Shankar Jothi ${ }^{1,2}$, A.R.Phani ${ }^{3}$ and D.B.Raju ${ }^{4}$ \\ 'School of Pharmacy, Masterskill University College of Health Science, Kualalumpur,43200, Malaysia \\ ${ }^{2}$ Faculty of Science, technology and engineering La' Trobe University,Bendigo Victoria 3552, Australia \\ ${ }^{3}$ Nano-Research for Advanced Materials and Technologies, Bangalore, 560040, Karnataka, India \\ ${ }^{4}$ Nanotechnology research centre, Shri Vishnu college of Pharmacy, Bhimavaram, 534202, Andhra Pradesh, India \\ * Corresponding author: gunnaeswara79@gmail.com
}

\begin{abstract}
Cerium oxide $\left(\mathrm{CeO}_{2}\right)$ nanoparticles having size range of $160 \mathrm{~nm}$ were prepared by using simple and effective sol-gel process and evaluated for their ulcer protective activity in an animal model. $\mathrm{CeO}_{2}$ nanoparticles at a dose of $1 \mathrm{mg} / \mathrm{kg}$ found to protect gastrointestinal mucosal from ethanol induced gastric ulcers. The ability of these nanoparticles to protect ethanol induced ulcers could be supported by increased amount of biomarkers in the native tissue like superoxide dismutase (SOD) (from $85.18 \pm 0.24$ to $103.18 \pm 0.42$ ) and Catalase (from $66.48 \pm 0.71$ to $85.88 \pm 0.61$ ) in Group 2 and Group 4. The percentage of ulcer inhibition of $\mathrm{CeO}_{2}$ nanoparticles is $80.2 \%$ which is also close to the standard drug ranitidine ( $87.9 \%$ ). The prepared nanoparticles were characterized by SEM and XRD. The probable mechanism may be due to the dual oxidation state of $\mathrm{CeO}_{2}$ which will help in scavenging reactive oxygen species (ROS) and reduce oxidative stress locally and also mimicking the intrinsic intracellular enzymes like SOD. All these results and properties could be useful in protecting the gastrointestinal mucosa from oxidative stress generated by ethanol.
\end{abstract}

Keywords: Cerium oxide nanoparticles, Gastric ulcers, Reactive oxygen species, Superoxide dismutase

Citation: R.G.S.V.Prasad et al. Cerium oxide Nanoparticles Protects Gastrointestinal Mucosa From Ethanol Induced Gastric Ulcers in In-vivo Animal Model. Nano Biomed. Eng. 2013, 5(1), 46-49. DOI: 10.5101/nbe.v5i1.p46-49.

\section{Introduction}

Alcohol consumption is one of the major independent risk factor for gastric ulcers and increases the risk especially in patients undergoing treatment with nonsteroidal anti-inflammatory drugs [1]. Ethanol is one of the exogenous entities that have long standing record to produce gastric damage. The nature and severity of gastric ulcer could be evaluated by ulcer lesions on gastrointestinal mucosa and histological changes [2]. One of the proposed mechanisms of ethanol induced ulcers is by oxidative damage and stress along with depletion of anti-oxidants in gastrointestinal mucosa $[3,4]$. Etiology of these ulcers are not only related to extrinsic factors like alcohol but also to various intrinsic protective factors like gastric mucosal barrier, oxidative stress in mucosa and mucosal hypoperfusion [5]. Among all these factors, reactive oxygen species (ROS) due to oxidative stress generated in the mucosal is major contributor for gastric ulcers [6].

Cerium oxide $\left(\mathrm{CeO}_{2}\right)$ nanoparticles are widely use in solid fuel cells, UV absorbers and in automobile indu- stries as free radical scavengers [7]. Taking this property into concern, in vitro free radical scavenging ability of $\mathrm{CeO}_{2}$ nanoparticles was studied on human breast cells in which the oxidative stress was induced by radiation and quite interestingly these nanoparticles protected these cells from radiation induced apoptotic cell death $[8,9]$. Reports revealed that $\mathrm{CeO}_{2}$ nanoparticles also protected myocardial cells from oxidative damage [10]. $\mathrm{CeO}_{2}$ nanoparticles also contribute to neuroprotection, a dose of $\mathrm{CeO}_{2}$ nanoparticles $(10 \mathrm{nM})$ protected rat spinal cord neurons from oxidative damage induced by $\mathrm{H}_{2} \mathrm{O}_{2}$ [11].

The ability of $\mathrm{CeO}_{2}$ nanoparticles to protect the oxidative damage from ROS was key factor for this research. Research suggests that nanoceria can exhibit dual oxidation state which accounts for their free radical scavenging activity and protection from oxidative stress induced locally. During the process of repair in oxidative damage intrinsic defense enzymes like superoxide dismutase (SOD) play a major role in scavenging excess free radicals. $\mathrm{CeO}_{2}$ nanoparticles were found to mimic 
the role of SOD where SOD concentration is depleted in extensive oxidative damage $[12,13]$. Moreover $\mathrm{CeO}_{2}$ nanoparticles also protected gastrointestinal epithelial cells from radiation induced damage [14]. In the present study we utilized the same principle in an animal model and tested the ability of $\mathrm{CeO}_{2}$ to protect the gastrointestinal mucosa against ethanol induced ulcers and evaluated biomarkers of oxidative damage like SOD and catalase. SEM and XRD were used to evaluate morphological characters of prepared $\mathrm{CeO}_{2}$ nanoparticles.

\section{Materials and methods}

\subsection{Preparation of $\mathrm{CeO}_{2}$ nanoparticles}

$10 \mathrm{~g}$ of cerium chloride $\left(\mathrm{CeCl}_{3}\right.$, Sigma Aldrich) was transferred into a $100 \mathrm{ml} 2$ neck flasks and add $20 \mathrm{ml}$ of 2-methoxy ethanol solvent (Sigma Aldrich) and stirred for 20 min. $3.5 \mathrm{~g}$ of CTAB (Sigma Aldrich) transfer into another $100 \mathrm{ml}$ beaker and dissolved in $10 \mathrm{ml}$ of 2-Methoxy ethanol solvent and stirred the contents for $10 \mathrm{~min}$. These solutions are mixed for $20 \mathrm{~min}$. To the above solution ammonia was added drop wise under constant stirring. The contents were filtered and wash several times with double distilled water (DD water). The precipitate was dried in the oven at $125{ }^{\circ} \mathrm{C}$ for $24 \mathrm{~h}$. The sample was heat treated in a furnace at $800{ }^{\circ} \mathrm{C}$ for 48 h. Prepared nanoparticles were evaluated by Scanning Electron Microscope (SEM) and XRD. SEM images of $\mathrm{CeO}_{2}$ nanoparticles were obtained by a Phillips SEM$535 \mathrm{M}$ microscope operating at an acceleration voltage of $20 \mathrm{kV}$. Powder X-ray diffraction (XRD) was carried out in a diffractometer using $\mathrm{CuKa}$ radiations at voltage $=40.0 \mathrm{kV}$ and current $=30 \mathrm{~mA}$ using BRUKER X-ray diffractometer.

\subsection{Animals}

Female Sprague-Dawley rats which are eight week old and weighing about (200-250 g) were purchased. All animals were maintained at temperature $25 \pm 1{ }^{\circ} \mathrm{C}$ and had free access to a diet and drinking water. All of the experimental procedures were performed in accordance with the Masterskill University guidelines for the welfare of experimental animals. Animal experimentation ethics approval MUCH/AEC/HS/2012/14.

\subsection{Ethanol induced ulcer model}

The method followed was based on previous research by M. Umamaheswari et al with slight modification [15]. All the animals were divided into four groups, each consisting of six rats. Prior to experimental procedures all the animals were fasted for $36 \mathrm{~h}$, the Group-1 (negative control group) received distilled water; Group-2 (positive control group) received ethanol. Group-3 of animals received ranitidine in the dose of $50 \mathrm{mg} / \mathrm{kg}$ as a reference drug [17]. Groups-4 received $1 \mathrm{mg} / \mathrm{kg} \mathrm{CeO}$ nanoparticles in saline, respectively. The dose of $\mathrm{CeO}_{2}$ was selected based on previous research by J. Colon et al and Hirst. S.M et al. We used a higher dose compared to them because of animal model used and route of administration [14,16].
Gastric ulcers were induced in Groups except in Group-1 by administrating $90 \%$ of ethanol orally, after 45 min of administration of alcohol ranitidine or $\mathrm{CeO}_{2}$ nanoparticles were given to the animals orally. They were kept in specially constructed cages to prevent coprophagia during and after the experiment. The animals were anaesthetized 1h latter with anesthetic ether and stomach was incised along the greater curvature and ulceration will be scored. A score for the ulcer was studied. The fundic part of the stomach is homogenized $(5 \%)$ in ice cold $0.9 \%$ saline with a potter-Elvehjem glass homogenizer for $30 \mathrm{sec}$. The homogenate were centrifuged at $800 \mathrm{~g}$ for $10 \mathrm{~min}$ followed by centrifugation of the supernatant at 12,000 $\mathrm{g}$ for $15 \mathrm{~min}$ in a sigma laboratory centrifuges $3 \mathrm{k} 30$ and the obtained mitochondrial fraction (14) and its subjected to antioxidants parameters such as Superoxide dismutase and Catalase. Percentage inhibition was calculated by using below formula.

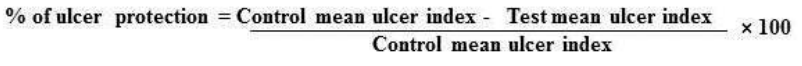

Ulcer scoring is numbered as following based on the morphological observation of the exposed gastric mucosa [18]. (Normal stomach -0, Red coloration -0.5, Spot ulcer -1 , Hemorrhagic streak -1.5 ,Ulcers $(<2 \mathrm{~mm})-2$, Ulcers $(>2<4)$ Perforation -3 ,Ulcers $(>4 \mathrm{~mm})-4$

\subsection{Superoxide dismutase assay}

$0.5 \mathrm{ml}$ of the tissue homogenate was added with 0.25 $\mathrm{ml}$ of absolute ethanol and $0.15 \mathrm{ml}$ of chloroform and allowed the reaction mixture to stand for $15 \mathrm{~min}$ under constant stirring, the resulting suspension was centrifuged and the supernatant was used for the enzyme assay. To 0.5 $\mathrm{ml}$ of the above solution $2 \mathrm{ml}$ of $0.1 \mathrm{M}$ Tris $\mathrm{HCl}$ buffer $0.5 \mathrm{ml}$ of pyrogallol was added and final volume was made to $4 \mathrm{ml}$ with distilled water. The rate of inhibition of pyrogallol auto-oxidation after the addition of the enzyme was noted at $470 \mathrm{~nm}$ at on interval of one minute for 3 min. The enzyme activity was expressed in terms of units/ $\mathrm{mg}$ protein and one unit corresponds to the amount of enzyme required to inhibit the auto oxidation reaction by $50 \%$.

\subsection{Catalase assay}

$0.1 \mathrm{ml}$ of the tissue homogenate was added with 1.0 $\mathrm{ml}$ of phosphate buffer and $0.5 \mathrm{ml}$ of $\mathrm{H}_{2} \mathrm{O}_{2}$. The reaction was assessed by the addition of $2 \mathrm{ml}$ of dichromate acetic acid reagent. Standard hydrogen peroxide in the range of 4 to $2 \mu \mathrm{M}$ were taken and treated similarly. The tubes were heated in a boiling water bath for $10 \mathrm{~min}$. The color developed was analyzed at $570 \mathrm{~nm}$ in a colorimeter. Catalase activity was expressed as $\mu$ moles of $\mathrm{H}_{2} \mathrm{O}_{2}$ utilized $/ \mathrm{min} / \mathrm{mg}$ protein under incubation condition.

\section{Results and discussions}

\subsection{Morphological properties}

The morphology of nanoparticles was observed using Phillips SEM-535M microscope operating at an 
http://nanobe.org

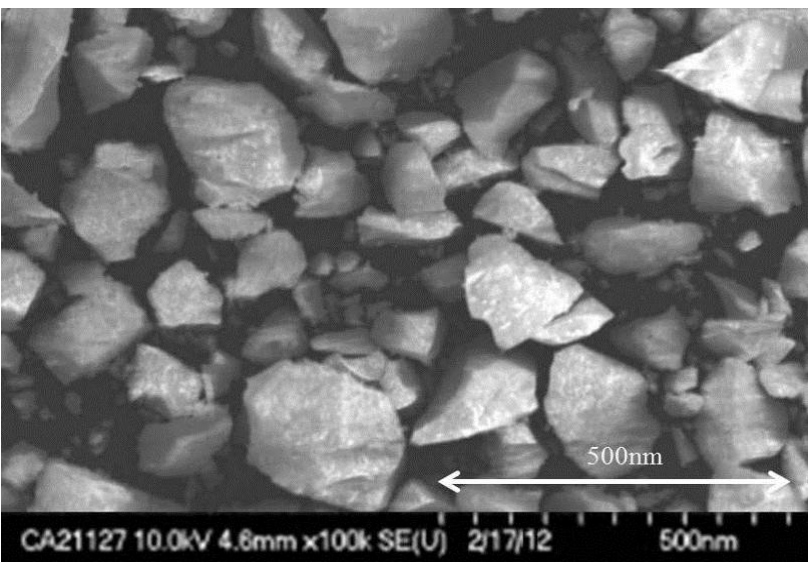

Fig. 1 SEM image of nanoparticles of $\mathrm{CeO}_{2}$ annealed at $800{ }^{\circ} \mathrm{C}$ for $48 \mathrm{~h}$

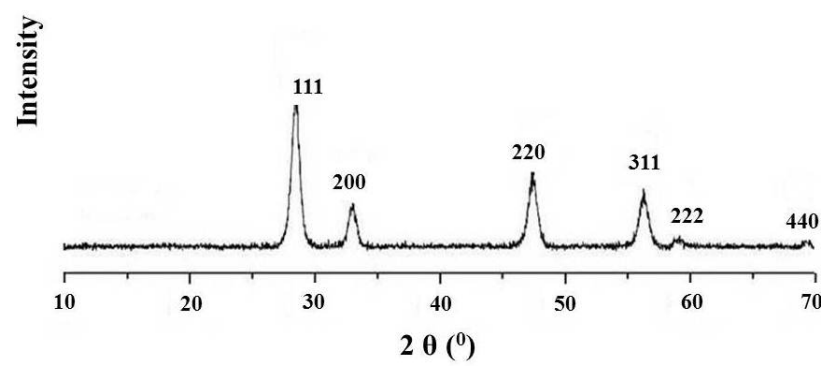

Fig. 2 XRD nanoparticles of $\mathrm{CeO}_{2}$ annealed at $800{ }^{\circ} \mathrm{C}$ for $48 \mathrm{~h}$.

acceleration voltage of $20 \mathrm{kV}$. The surface morphology of prepared ceria is presented in the Fig. 1 SEM micrograph clearly shows $\mathrm{CeO}_{2}$ nanoparticles with average particle size of the $160 \mathrm{~nm}$

\subsection{XRD}

Fig. 2 shows the powder XRD pattern of the prepared $\mathrm{CeO} 2$ nanoparticles. From this figure, the characteristic peaks are located at $2 \theta=28.5,33.9,47.8,56.2,58.5$ and 69.10 and they correspond to (111), (200), (220), (311), (222) and (400) lattice planes, respectively. All the reflections of powder XRD pattern of the sample of this work were indexed using the INDEXING software package. The lattice parameters from powder XRD data were found using the UNITCELL software package and the obtained values were found to be $\mathrm{a}=\mathrm{b}=\mathrm{c}=5.416 \AA$, $\alpha=\beta=\gamma=90^{\circ}$. The obtained lattice parameters for ceria nanoparticles are observed to be in good form [9].

\subsection{Ulcer index and percentage inhibition}

Animals in Group-2 after oral administration of ethanol produced characteristic lesions in the glandular portion of the stomach which appeared as elongated bands of thick, black \& dark red lesions (Fig. 3b). While control Group-1 did not show any lesions (Fig. 3a). $\mathrm{CeO}_{2}$ nanoparticles (a dose of $1 \mathrm{mg} / \mathrm{kg}$ ) showed significant protection (Fig. $3 \mathrm{c}$ ) index of $80.2 \%$ (Table 1 ) in comparison to control, whereas Ranitidine (dose $50 \mathrm{mg} / \mathrm{kg}$ ) as reference standard drug was showed protection index of $87.9 \%$ (Table 1).

Table 1 Effect of $\mathrm{CeO}_{2}$ nanoparticles in ethanol induced gastric ulcers.

\begin{tabular}{|l|l|l|l|}
\hline Group & Treatment & Ulcer Index $*$ & $\%$ inhibition \\
\hline 1 & Distilled water & - & - \\
\hline 2 & Alcohol & $18.2 \pm 0.3$ & - \\
\hline 3 & Ranitidine $50 \mathrm{mg} / \mathrm{kg}$ & $2.2 \pm 0.4$ & $87.9 \%$ \\
\hline 4 & $\mathrm{CeO}_{2}$ nanoparticles $1 \mathrm{mg} / \mathrm{kg}$ & $3.6 \pm 0.3$ & $80.2 \%$ \\
\hline
\end{tabular}

\subsection{SOD and Catalase analysis results}

Intrinsic antioxidant enzymatic levels (SOD and Catalase) were measured from the tissue isolates revealed that animal group treated with distilled water has highest amount of SOD and Catalase levels indicating that there is no damage to the native tissue. The amount of these antioxidant enzymes decreased in other treated groups (shown in Table 2). In Group-2 which is treated with alcohol alone there is drastic fall in both enzymatic levels $(112.42 \pm 0.36$ to $85.18 \pm 0.24$ for SOD and $95.19 \pm 0.94$ to $66.48 \pm 0.71$ for Catalase) leading to conclusion that the amount of oxidative damage is more. In Group- 3 and 4 the levels of these antioxidant enzymes are found to be higher than that of Group-2 because they are either treated with standard drug ranitidine or $\mathrm{CeO}_{2}$ nanoparticles. When compared to Group-4 (1 mg/ $\mathrm{kg}$ ) which is treated with $\mathrm{CeO}_{2}$ Group-3 has better antioxidant levels this may be accounted to the low dose $(1 \mathrm{mg} / \mathrm{kg})$ of $\mathrm{CeO}_{2}$ nanoparticles given to the animals.

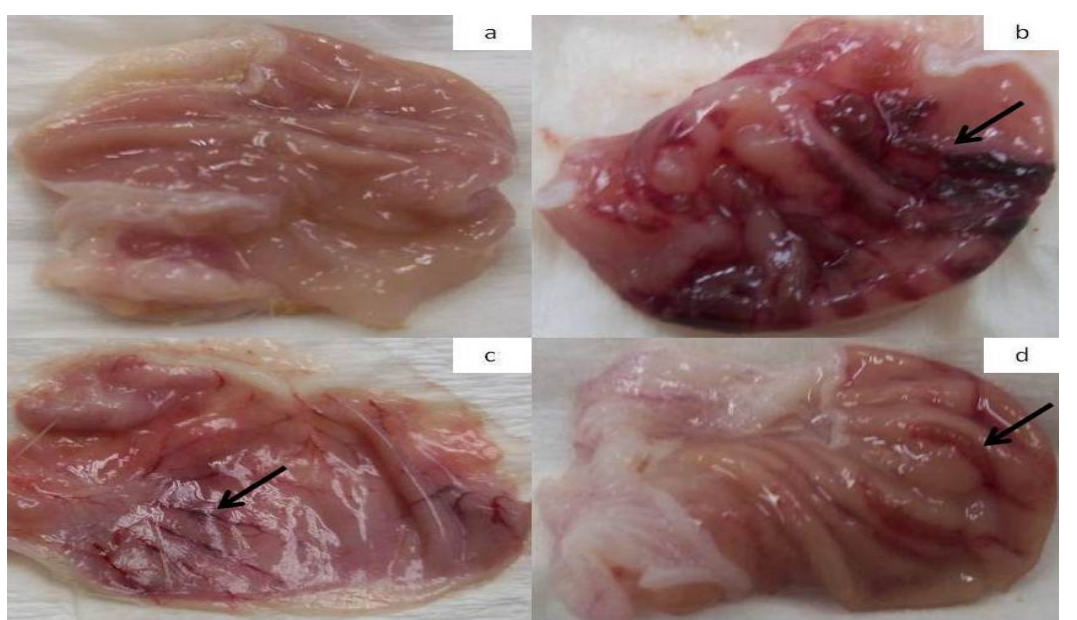

Fig. 3 Photograph showing exposed part of gastric mucosa (a) Control, (b) treated with ethanol, (c) treated with $\mathrm{CeO}_{2}$ nanoparticles, (d) treated with ranitidine. Arrows indicating the damaged part of gastrointestinal mucosa 
Table 2 Effect of $\mathrm{CeO}_{2}$ nanoparticles on SOD and catalase levels on ethanol induced gastric ulcers.

\begin{tabular}{|l|l|l|l|}
\hline Group & Treatment & SOD* & Catalase* \\
\hline 1 & Distilled water & $112.42 \pm 0.36$ & $95.19 \pm 0.94$ \\
\hline 2 & Alcohol & $85.18 \pm 0.24$ & $66.48 \pm 0.71$ \\
\hline 3 & Ranitidine $50 \mathrm{mg} / \mathrm{kg}$ & $109.18 \pm 0.50$ & $93.38 \pm 1.04$ \\
\hline 4 & $\mathrm{CeO}_{2}$ nanoparticles $1 \mathrm{mg} / \mathrm{kg}$ & $103.18 \pm 0.42$ & $85.88 \pm 0.61$ \\
\hline
\end{tabular}

*values are expressed as mean \pm standard error of the mean; $(n=6)$ animals in each group.

The ability of $\mathrm{CeO}_{2}$ nanoparticles to protect gastrointestinal mucosa from oxidative stress may be due to its dual oxidation states $\left(\mathrm{Ce}^{3+}\right.$ and $\left.\mathrm{Ce}^{4+}\right)$ [9,20].This dual oxidation state may help in exhibiting an antioxidant activity. Furthermore nanoceria can change oxidation state from $\mathrm{Ce}^{3+}$ to $\mathrm{Ce}^{4+}$ which results in free radical scavenging activity which is useful in scavenging reactive oxygen species at the site of damage [19]. Some researchers also believe that nanoceria can exhibit autoregenerative activity by interconverting their oxidation states. This may be one of the potential reasons for free radical scavenging activity of nanoceria [9]. $\mathrm{CeO}_{2}$ also know to mimic the role of SOD in biological entities this could also be a major reason for its ulcer protective activity $[12,13]$. These results were supported by the work done by $\mathrm{J}$. Colon et al in which they used nano ceria to protect gastrointestinal mucosa from radiation induced damage. Radiation induced damage and ethanol induced damage corresponds to similar oxidative stress at cellular level which proves the relation between these two works. Nano cerial are also used to protect various cells from various oxidative stress created by various entities $[10,11]$.

\section{Conclusions}

We have successfully prepared $\mathrm{CeO}_{2}$ nanoparticles and evaluated their antiulcer activity in an animal model. Results showed the $\mathrm{CeO}_{2}$ nanoparticles under a very low dose $(1 \mathrm{mg} / \mathrm{kg})$ when compared to standard drug ranitidine $(50 \mathrm{mg} / \mathrm{kg})$ could protect gastrointestinal mucosa from oxidative damage caused by ethanol. In our present results the effectiveness of $\mathrm{CeO}_{2}$ nanoparticles is low compared to that of standard drug ranitidine because of dose variation .If the dose of these nanoparticles could be increase we could replicate similar results as that of ranitidine.

\section{Acknowledgements}

The authors are grateful to the management of the Masterskill university of health science, Malaysia for promoting research and providing financial support in carrying out this investigation and NanoRAM Technologies,Bangalore, Karnataka State, India for their technical support.

\section{References}

1 Kaufman D.W., Kelly. J.P., Wiholm B.E., Sheehan J.E., Koffr S., Shapipo S. The risk of acute major upper gastrointestinal bleeding among users of aspirin and ibuprofen at various levels of alcohol consumption. Am. J. Gastroenterol. 1999. 94(11): 3189-3196.

2 Mitsuyama M., Tsuruta O., Matsui Y., Harada K., Tomiyasu N., Suzuki A., Takaki K., Masuda J., Handa K., Satoh Y., Bennett B.L., Toyonaga A., Sata M. Activation of c-Jun N-terminal kinase
(JNK) signalling in experimentally induced gastric lesions in rats. Clin. Exp. Immunol. 2005. 143(1): 24-29.

3 Hirokawa M., Miura S., Yoshida H., Kurose I., Shigematsu T., Hokari R., Higuchi H.,Watanabe N., Yokoyama Y., Kimura H., Kato S., Ishii H. Oxidative stress and mitochondrial damage precedes gastric mucosal cell death induced by ethanol administration. Alcohol. Clin. Exp. Res.1998. 22(3): 111-114.

4 Alarcón de la Lastra C., La Casa C., Martin M.J., Motilva V. Effects of cinitapride on gastric ulceration and secretion in rats. Inflamm. Res. 1998. 47(3): 131-136.

5 Ham M., Kaunitz J. Gastroduodenal defense. Curr. Opin. Gastroenterol.2007. 23(6): 607-616

6 Franke A., Teyssen S., Singer M.V. Alcohol-related diseases of the esophagus and stomach. Dig. Dis. 2005. 23(3-4): 204-213.

7 Otsuka K., Ushiyama T., Yamanaka I. Partial oxidation of methane using the redox of cerium oxide. Chem Lett. 1993.22(9):1517-1520

8 Rzigalinksi B.A., Meehan K., Davis R.M., Xu Y., Miles W.C., Cohen C.A. Radical nanomedicine. Nanomedicine. 2006.1(4): 399-412

9 Tarnuzzer R.W., Colon J., Patil S., Seal S. Vacancy engineered ceria nanostructures for protection from radiation-induced cellular damage Nano Lett. 2005.5(12): 2573-2577

10 Jianli N., Azfer A., Rogers L.M., Wang X., Kolattukudy P.E. Cardioprotective effects of cerium oxide nanoparticle in a transgenic murine model of cardiomyopathy. Cardiovasc. Res. 2007. 73(3): 549-559

11 Das M., Bhargava N., Gregory C., Riedel L., Molnar P., Hickman J.J. Adult rat spinal cord culture on an organosilane surface in a novel serum-free medium. In Vitro Cell Dev Biol Anim. 2005.41(10): 343-348

12. Korsvik C., Patil S., Seal S., Self W.T. Superoxide dismutase mimetic properties exhibited by vacancy engineered ceria nanoparticles. Chem Commun (Camb). 2007.14(10):1056-1058

13 Heckert E.G., Karakoti A.S., Seal S., Self W.T. The role of cerium redox state in the SOD mimetic activity of nanoceria. Biomaterials. 2008. 29(18): 2705-2709

14 Colon J., Hsieh N., Ferguson A., Kupelian P., Seal S., Jenkins D.W., Baker C.H. Cerium oxide nanoparticles protect gastrointestinal epithelium from radiation-induced damage by reduction of reactive oxygen species and upregulation of superoxide dismutase. Nanomedicine.2010. 6(5): 698-705

15 Umamaheswari M., Asok kumar K., Rathidevi R., Sivashanmugam A.T., Subhadradevi V., Ravi T.K. Antiulcer and in vitro antioxidant activities of Jasminum grandiflorum L. J. Ethnopharmacol. 2007. 110(3): 464-470

16 Hirst S.M., Karakoti A., Singh S., Self W., Tyler R., Seal S., Reilly C.M. Bio-distribution and in vivo antioxidant effects of cerium oxide nanoparticles in mice. Environ. Toxicol. 2011.28(2).107-18

17 Gill N. S., Marwah N., Rashmi A., Bali M. Study of Antioxidant, Analgesic and Antiulcer Potential of Trichosanthes cucumerina Ethanolic Seeds Extract. Asian J Plant Sci. 2012. 11(5): 235-240

18 Hikino H. Editor, Recent research on Oriental medicinal plants in Economic Medical Plant Research, Vol 1, Academic press, London, (1985).

19 Chen J., Patil S., Seal S., McGinnis J.F. Rare earth nanoparticles prevent retinal degeneration induced by intracellular peroxides. Nat Nanotechnol. 2006. 1: 142-150

20 Revathy D., Prasad R.G.S.V., Jakka V.S., Aparna R.S.L., Phani A.R., Jacob B., Salins P.C., Raju D.B. Cerium Oxide Nanoparticles Promotes Wound Healing Activity in In-Vivo Animal Model. J. Bionanosci.2012. 6(2): 78-83

Copyright:(c) 2013 R.G.S.V.Prasad et al. This is an open-access article distributed under the terms of the Creative Commons Attribution License, which permits unrestricted use, distribution, and reproduction in any medium, provided the original author and source are credited. 